\title{
Publisher Correction: Relating pattern deviancy aversion to stigma and prejudice
}

Anton Gollwitzer (D), Julia Marshall, Yimeng Wang and John A. Bargh

Correction to: Nature Human Behaviour https://doi.org/10.1038/s41562-017-0243-x, published online 27 November 2017.

In the version of this article initially published, error shading in Fig. 2 was not correct. The error has been corrected in the PDF and HTML versions of this article.
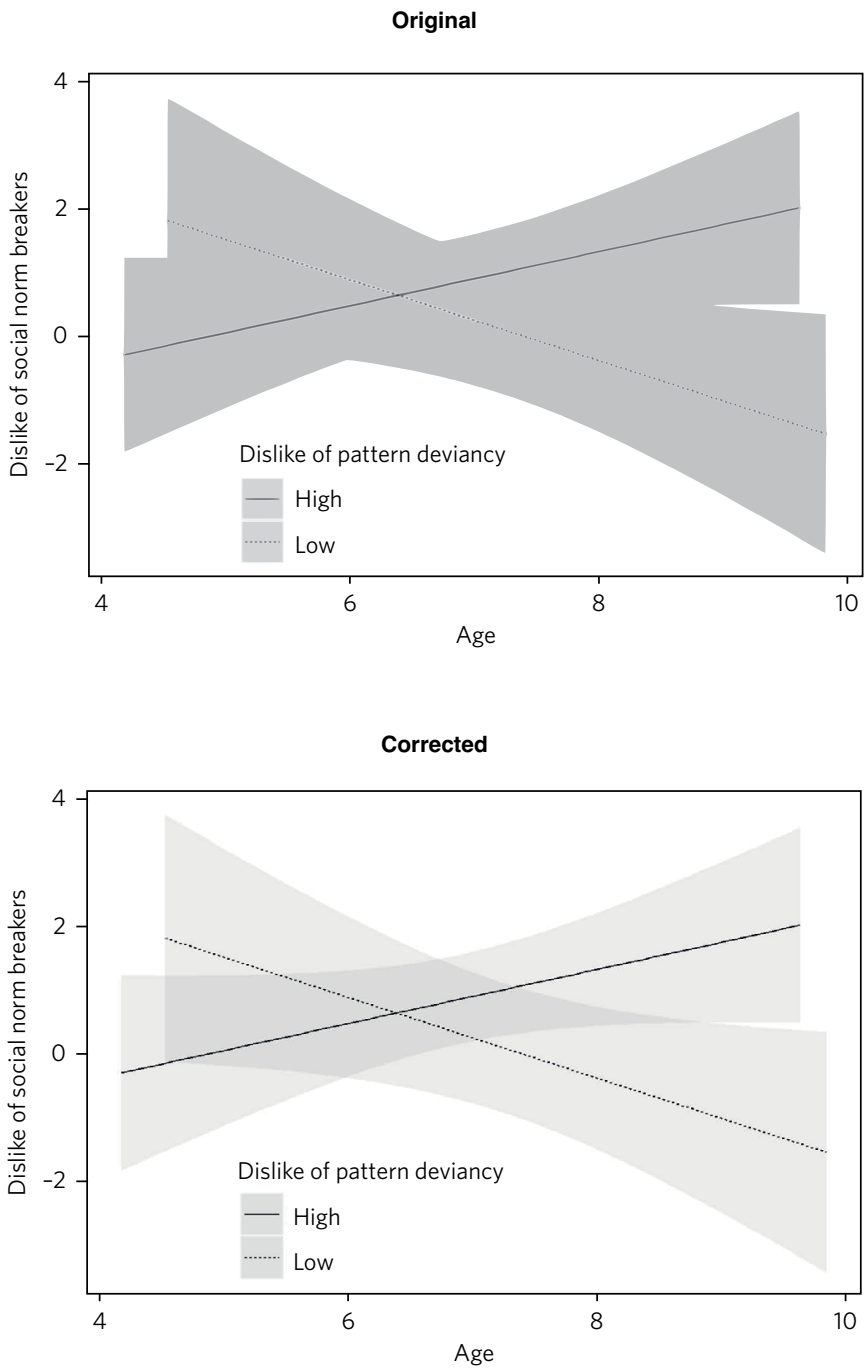

Fig. 2 | Original and Corrected.

Published online: 10 December 2020

https://doi.org/10.1038/s41562-020-01028-X

๑ The Author(s), under exclusive licence to Springer Nature Limited 2020 